\title{
PREFACE: TECHNICAL COMMISSION V
}

\author{
A. Senthil Kumar ${ }^{1}$, Sheryl Rose Reyes ${ }^{2}$ \\ ${ }^{1}$ President, ISPRS Technical Commission V - Indian Space Research Organisation 4 Kalidas Road, Dehradun, India - \\ isprs-pr-c5@isprs.org \\ ${ }^{2}$ ISPRS Student Consortium President - United Nations University - Institute for the Advanced Study of Sustainability, \\ 5 Chome-53-70 Jingumae, Shibuya City, Tokyo, Japan - sherylrose.reyes@gmail.com
}

Capacity Building in promoting Geo-information science and technology (GIST) has its significance in ensuring good governance and resources management at local, regional and global scales. To emphasize this strongly in young generation, the International Society for Photogrammetry and Remote Sensing (ISPRS) has been engaged for more than 18 years by having an exclusive Technical Commission on Education and Outreach elements. Every 4 years, this Commission has been addressing different aspects of GIST by setting up theme specific Working Groups (WGs).

ISPRS Technical Commission V (TC-V) on Education and Outreach (2016-2022) has constituted eight theme WGs with international experts to promote as well as explore new methods of capacity development relevant to GIST. These WGs have made significant contributions by engaging actively workshops and new scientific initiatives in past five years. ISPRS Student Consortium (SC) is part of the Commission, and promotes the profession to the youth. The Consortium serves as a platform of communication and information exchange among members, enabling professional networking and fostering collaborations.

We are happy to note that for ISPRS Congress 2021, there were 18 submissions of research papers on Education and Outreach. Of these, 7 were accepted for Archives and 3 for Annals. In these, 3 papers were submitted and accepted under the Youth Forum track. All these papers were reviewed by selected experts. The Youth Forum papers include the use of Google Earth Engine for agricultural drought, InSAR data for deriving digital elevation model and free and open-source platforms for image processing and the potential of radar remote sensing in image classification and topographic mapping. several disciplines covering expanded Body of Knowledge for geoinformatics, software design tool for remote sensing image processing, design of a terrestrial laser scanner simulator as an educational tool, the use of UAV based photogrammetry suite for providing location based services to highly vulnerable communities, machine learning based tools in WebGIS, and survey based gender inequality in academic career in GIST.

Besides these technical papers, there was one paper entitled "55 years in ISPRS: The Ambassador of our Profession" highlighting the illustrious journey and pioneering contributions of Dr. Gottfried Konecny in the field of GIST. Dr. Gottfried is also presently serving as Co-Chair of TCV WG on Innovative technologies in training civil engineers and architects. Another paper by Student Consortium members describes how public-private cooperation models would mutually benefit the two communities in accessing and exploiting geospatial data for societal and business applications.

We sincerely thank all the reviewers and acknowledge strong efforts made by Area Chairs to ensure quality of all accepted papers. We greatly appreciate the perseverance and dedication of the Scientific and Organizing Committee. We are confident that the present 2021 virtual edition of ISPRS Congress Proceedings will serve as platform for discussion on the current research efforts on the Education and Outreach themes cutting across different disciplines. 